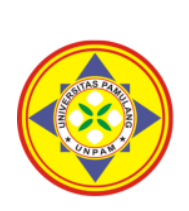

\title{
PENGARUH LOAN TO DEPOSIT RATIO (LDR) DAN CAPITAL ADEQUACY RATIO (CAR) TERHADAP RETURN ON ASSET (ROA) PADA PT. BANK TABUNGAN NEGARA (PERSERO), TBK PERIODE 2010-2019
}

\author{
${ }^{1 *}$ Rahmat Subur, ${ }^{2}$ Muhamad Anwar \\ Universitas Pamulang, Tangerang Selatan, Banten, Indonesia \\ *dosen01356@unpam.ac.id
}

\begin{abstract}
Abstrak
Penelitian ini bertujuan untuk mengetahui pengaruh Loan to Deposit Ratio (LDR) dan Capital Adequacy Ratio (CAR) terhadap Return On Asset (ROA) pada PT Bank Tabungan Negara (Persero) Tbk Periode 2010-2019. Jenis penelitian ini adalah kuantitatif. Metode yang digunakan adalah metode Regresi Linier Berganda yang dilakukan dengan menggunakan uji $t$ dan uji $f$ dengan variabel $\backslash$ mathrm $\{X\}_{-} \backslash$ mathrm $\{1\}$ Loan to Deposit Ratio (LDR), variabel $\backslash$ mathrm $\{X\}_{-} \backslash \operatorname{mathrm}\{2\}$ Capital Adequacy Ratio (CAR), dan variabel Y Return On Asset (ROA). Jenis data yang digunakan adalah data sekunder. Hasil penelitian menunjukkan bahwa secara parsial variabel Loan to Deposit Ratio (LDR) berpengaruh negatif dan signifikan terhadap Return On Asset (ROA) ini ditunjukkan oleh hasil uji t dengan nilai signifikan LDR sebesar 0,002 < 0,05 dan nilai \mathrm\{t\}_\{\mathrm\{hitung\}\} 4,924 > t_\{tabel\} 2,365, maka ho1 ditolak ha1 diterima. Sedangkan secara parsial variabel Capital Adequacy Ratio (CAR) tidak berpengaruh terhadap Return On Asset (ROA) ini ditunjukkan oleh hasil uji t dengan nilai signifikan CAR sebesar 0,758 >0,05 dan nilai t_\{hitung\} 0,320<t_\{tabel\} 2,365, maka ho2 diterima ha2 ditolak. Secara simultan variabel Loan to Deposit Ratio (LDR) dan Capital Adequacy Ratio (CAR) berpengaruh positif dan signifikan terhadap Return On Asset (ROA) ini ditunjukkan oleh hasil uji $\mathrm{f}$ dengan nilai signifikan 0,005 $<0,05$ dan nilai f_\{hitung\} 12,126 > f_\{tabel\} 4,46, maka ho3 ditolak ha3 diterima. Loan to Deposit Ratio (LDR) dan Capital Adequacy Ratio (CAR) terhadap Return On Asset (ROA) dengan koefisien determinasi $\mathrm{KD}=77,6 \%$, sedangkan sisanya $22,4 \%$ dipengaruhi oleh faktor lain.
\end{abstract}

Kata Kunci: Loan to Deposit Ratio (LDR), Capital Adequacy Ratio (CAR), Return On Asset (ROA)

\section{Abstract}

This study aims to determine the effect of Loan to Deposit Ratio (LDR) and Capital Adequacy Ratio (CAR) on Return On Assets (ROA) at PT Bank Tabungan Negara (Persero) Tbk Period 2010-2019. This type of research is quantitative. The method used is the Multiple Linear Regression method using the $t$ test and $f$ test with the variable $\mid$ mathrm $\{X\}_{-} \mid$mathrm $\{1\}$ Loan to Deposit Ratio (LDR), variable |mathrm $\{X\}_{-} \mid$mathrm $\{2\}$ Capital Adequacy Ratio (CAR), and variable Y Return On Assets (ROA). The type of data used is secondary data. The results showed that partially the Loan to Deposit Ratio (LDR) variable had a negative and significant effect on Return On Assets (ROA) as indicated by the results of the test with a significant LDR value of $0.002<0.05$ and the value |mathrm\{t\}_\{ |mathrm\{count\}\} 4,924 > t_\{table\} 2,365, then ho1 is rejected ha1 is accepted. While partially the Capital Adequacy Ratio (CAR) variable has no effect on Return On Assets (ROA), this is indicated by the results of the $t$ test with a significant $C A R$ value of $0.758>0.05$ and the value of $t$ _\{count $\} 0.320<t$ _t table\} 2.365, ho2 accepted ha2 rejected. Simultaneously, the Loan to Deposit Ratio (LDR) and Capital Adequacy Ratio (CAR) variables have a positive and significant effect on Return On Assets (ROA) as indicated by the results of the $f$ test with a significant value of $0.005<0.05$ and a value of $f_{-}\{$count $\} 12.126>f_{-}\{$table $\} 4.46$, then ho3 is rejected ha3 is accepted. Loan to Deposit Ratio (LDR) and Capital Adequacy Ratio (CAR) to Return On Assets (ROA) with coefficient of determination $K D=77.6 \%$, while the remaining $22.4 \%$ is influenced by other factors. Keywords: Loan to Deposit Ratio (LDR), Capital Adequacy Ratio (CAR), Return On Assets (ROA) 


\section{PENDAHULUAN}

Pada Perbankan memiliki peranan yang sangat vital dalam menunjang perekonomian suatu negara, hampir setiap dari aspek kehidupan berhubungan dengan jasa perbankan. Jasa perbankan mampu membantu pembangunan suatu negara karena sesuai fungsinya sebagai lembaga intermediasi. Perbankan sebagai lembaga intermediasi atau penghubung antara pihak yang memiliki dana dan pihak yang membutuhkan dana, maka pengelolaan dan perkembangannya menjadi sorotan banyak pihak.

PT. Bank Tabungan Negara (Persero) Tbk adalah salah satu bank BUMN yang ada di Indonesia dan berbentuk perseroan terbatas bergerak dibidang jasa keuangan perbankan yang kegiatannya menghimpun dana dari masyarakat berupa tabungan, deposito, giro, dan investasi kemudian menyalurkannya kepada masyarakat berupa pemberian kredit. Salah satu program PT Bank Tabungan Negara (Persero) Tbk dalam pemberian kredit yaitu berupa KPR (kredit perumahan rakyat) yang dimana dalam pemberian kredit ini dapat beresiko terjadinya kredit bermasalah yang dilakukan oleh para debitur.

Laba PT Bank Tabungan Negara (Persero) Tbk turun dalam untuk buku tahun 2019. Penyebab penurunan laba tersebut karena perseroan melakukan bersih-bersih kredit macet. Direktur Keuangan PT Bank Tabungan Negara (Persero) Tbk Nixon Napitupulu menjelaskan, laba BTN di 2019 tercatat Rp 209 miliar. Angka tersebut turun 92,55 persen jika dibandingkan dengan setahun sebelumnya yang tecatat Rp 2,81 triliun. Nixon menjelaskan, penurunan laba karena perseroan menerapkan Pedoman Standar Akutansi Keuangan (PSAK) 71. Dalam PSAK 71 tersebut, bank harus memiliki cadangan kerugian penurunan nilai (CKPN) yang memadai dengan coverage harus di atas 100 persen di awal tahun 2020.

Berikut ini adalah data rasio keuangan Loan to Deposit Ratio (LDR) dan Capital Adequacy Ratio (CAR) dan Return On Assets (ROA) yang ada pada PT Bank
Tabungan Negara (Persero) Tbk Periode 2010-2019.

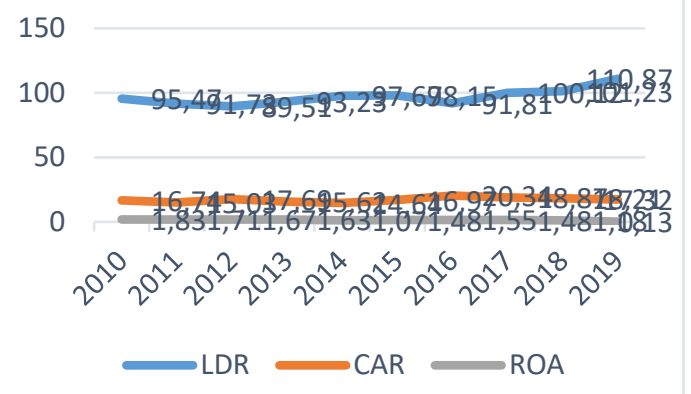

Gambar 1. Data Rasio Keuangan Loan to Deposit Ratio (LDR) dan Capital Adequacy Ratio (CAR) dan Return On Assets (ROA)

Berdasarkan gambar diatas dapat dilihat nilai Loan to Deposit Ratio (LDR), Capital Adequacy Ratio (CAR) dan Return On Assets (ROA) pada PT. Bank Tabungan Negara (Persero) Tbk dari tahun ke tahun selalu terjadi pergerakan. Pada rasio Loan to Deposit Ratio (LDR) dapat dilihat pada grafik diatas dari tahun 2010-2019 cenderung meningkat, walaupun terjadi fluktuatif setiap tahunnya dengan nilai terendah ditahun 2013 sebesar 89,51\% dan nilai tertinggi ditahun 2019 sebesar 110,87\%. Begitu juga nilai Capital Adequacy Ratio (CAR) tidak jauh berbeda dengan Loan to Deposit Ratio (LDR) setiap tahun terjadi fluktuatif dan cenderung meningkat dari tahun 2010-2019 dengan nilai terendah $14,64 \%$ dan nilai tertinggi 20,34\%. Sedangkan nilai Return On Assets (ROA) dari tahun 2010-2019 pada grafik menunjukkan setiap tahun terjadi fluktuatif dan cenderung menurun dengan nilai terendah $0,13 \%$ dan nilai tertinggi $1,83 \%$.

Berdasarkan uraian permasalahan tersebut, penulis tertarik untuk mengangkat judul "Pengaruh Loan to Deposit Ratio (LDR) dan Capital Adequacy Ratio (CAR) terhadap Return On Asset (ROA) pada PT Bank Tabungan Negara (Persero) Tbk Periode 2010 -2019".

\section{TINJAUAN PUSTAKA}

\section{Bank}

Menurut Undang-undang No. 10 tahun 1998 "Bank adalah badan usaha yang menghimpun dana dari masyarakat dalam bentuk simpanan dan 
menyalurkannya kepada masyarakat dalam bentuk kredit dan atau bentukbentuk lainnya dalam rangka meningkatkan taraf hidup rakyat banyak.

\section{Laporan Keuangan}

Menurut Fahmi (2014:22) “laporan keuangan merupakan suatu informasi yang menggambarkan kondisi suatu perusahaan dimana selanjutnya akan menjadi suatu informasi yang menggambarkan tentang kinerja suatu perusahaan".

Menurut Kasmir (2018:7) “laporan keuangan adalah laporan yang menunjukkan kondisi keuangan perusahaan pada saat ini atau dalam periode tertentu". Sedangkan menurut Sutrisno (2013:9) "laporan keuangan adalah hasil akhir dari proses akutansi yang meliputi dua laporan utama yaitu neraca dan laporan laba rugi".

\section{Analisis Rasio Keuangan}

Menurut Kasmir (2018:104), "rasio keuangan merupakan kegiatan membandingkan angka-angka yang ada dalam laporan keuangan dengan cara membagi satu angka dengan angka lainnya". Menurut Fahmi (2014:106), "rasio keuangan adalah hasil yang diperoleh dari perbandingan jumlah, dari satu jumlah dengan jumlah lainnya".

\section{Loan to Deposit Ratio}

Menurut Hariyani (2010:56) “Loan to Deposit Ratio (LDR) merupakan rasio kredit yang diberikan terhadap dana pihak ketiga yang diterima oleh bank yang bersangkutan". Besarnya Loan to Deposit Ratio (LDR) akan berpengaruh terhadap laba melalui penciptaan kredit. Menurut Kasmir (2018;226), "Loan to Deposit Ratio (LDR) dapat diukur dari perbandingan antara total kredit yang diberikan terhadap total dana pihak ketiga dan modal sendiri", dapat dirumuskan sebagai berikut: LDR $=\backslash$ frac $\{$ Total $\backslash \quad$ Kredit $\}\{$ Total $\backslash$ Simpanan+Ekuitas\}x100\%

Bank Indonesia selaku otoritas moneter menetapkan per tanggal 1
Maret 2011 akan memberlakukan peraturan Otorisasi Jasa Keuangan (POJK) Nomor 12/19/PBI/2010 yang berisi ketentuan Loan to Deposit Ratio (LDR) pada tingkat 78\%-110\%.

\section{Capital Adequacy Ratio}

Menurut Peraturan Bank Indonesia Nomor 15/12/PBI/2013 menetapkan Capital Adequacy Ratio (CAR), yaitu kewajiban penyediaan modal minimum yang harus dipertahankan oleh setiap bank sebagai suatu proporsi tertentu dari total aktiva tertimbang menurut risiko (ATMR) sebesar $8 \%$.

Menurut Hariyani (2010:51) “Capital Adequacy Ratio (CAR) atau rasio kecukupan modal merupakan rasio yang memperlihatkan seberapa besar jumlah seluruh aktiva bank yang mengandung risiko (kredit, penyertaan, surat berharga, dan tagihan pada bank lain) ikut dibiayai dari modal sendiri di samping memperoleh dana-dana dari sumber-sumber di luar bank".

Perhitungan rasio Capital Adequacy Ratio (CAR) sesuai dengan Surat Edaran Bank Indonesia Nomor 13/24/DPNP Tahun 2011 sebagai berikut:

\section{CAR $=\backslash$ frac $\{$ Modal $\}\{A T M R\} \times 100 \%$}

\section{Return On Asset}

Menurut Hariyani (2010:53) "rasio Return On Assets (ROA) merupakan rasio yang digunakan untuk mengukur kemampuan manajemen bank dalam memperoleh keuntungan (laba sebelum pajak) yang dihasilkan dari rata-rata total asset bank yang bersangkutan". Berdasarkan Surat Edaran Bank Indonesia Nomor 13/24/DPNP Tanggal 25 Oktober 2011, Return On Assets (ROA) merupakan perbandingan antara laba sebelum pajak dengan rata-rata asset dalam suatu periode yang dapat dihitung dengan rumus sebagai berikut: $\mathrm{ROA}=\backslash$ frac $\{$ Laba $\backslash$ sebelum $\backslash$ pajak $\}\{$ Total $\backslash$ asset $\} \times 100 \%$

\section{METODE}


Jenis penelitian ini adalah dengan melakukan penelitian deskriptif kuantitatif. Penelitian deskriptif kuantitatif bertujuan untuk menjelaskan tentang fenomena yang ada menggunakan perhitungan angkaangka dari sampel data yang telah dipilih dalam penyusunan penelitian ini. Menurut Sugiyono (2019:126) "populasi adalah wilayah generalisasi yang terdiri atas: objek atau subyek yang mempunyai kuantitas dan karakteristik tertentu yang ditetapkan oleh peneliti untuk dipelajari dan kemudian ditarik kesimpulannya". Menurut sugiyono (2019:127) "sampel adalah suatu bagian dari jumlah dan karakteristik yang dimiliki oleh populasi tersebut". Penelitian ini merupakan jenis penelitian kuantitatif dengan menggunakan SPSS (Statistical Package for the Social Sciences) Versi 26. Data yang digunakan dalam penelitian ini adalah time series.

\section{HASIL DAN PEMBAHASAN}

\section{Statistik Deskriptif}

Jumlah data atau sampel yang digunakan sebanyak 10, Loan to Deposit Ratio (LDR) memiliki nilai minimum sebesar 89,51, nilai maksimum sebesar 110,87 , range sebesar 21,36, sum sebesar 969,79 , mean sebesar 96,9790 , dan standar deviasi sebesar 6,22838. Capital Adequacy Ratio (CAR) memiliki nilai minimum sebesar 14,64, nilai maksimum sebesar 20,34, range sebesar 5,70, sum sebesar 171,43 , mean sebesar 17,1430, dan standar deviasi sebesar 1,76112. Return On Asset (ROA) memiliki nilai minimum sebesar 0,13 , nilai maksimum sebesar 1,83 , range sebesar 1,70, sum sebesar 13,73, mean sebesar 1,3730, dan standar deviasi sebesar 0,49498.

\section{Uji Asumsi Klasik}

a. Uji Normalitas

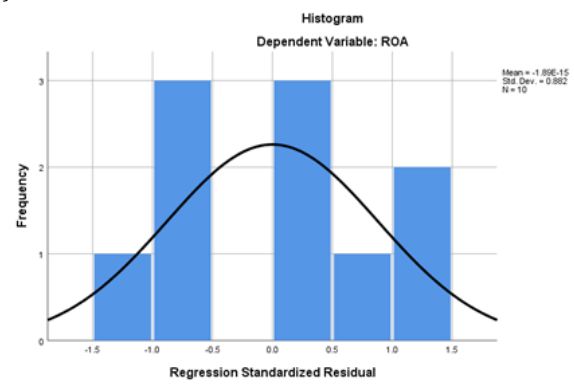

Gambar 2. Uji Normalitas

Berdasarkan grafik histogram pada gambar diatas, residual data telah menunjukkan kurva normal, karena kurva tidak miring ke kiri maupun ke kanan akan tetapi kurva lebih cenderung ke tengah dan berbentuk seperti lonceng. Selain grafik histogram, uji normalitas dapat juga menggunakan analisis statistik Pplot yang dapat dilihat pada gambar dibawah ini:

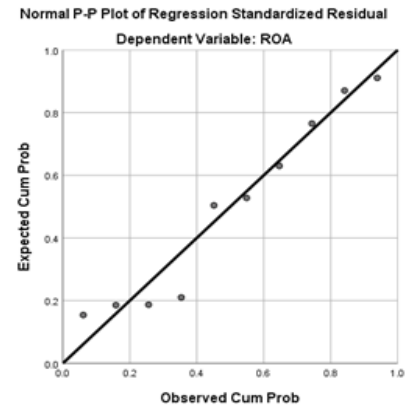

Gambar 3. Grafik Histogram

Dapat dilihat dari grafik normal p-plot pada gambar diatas, titik penyebaran data berada disekitar garis diagonal yang menunjukkan bahwa nilai residual berdistribusi normal. Untuk mendapatkan hasil uji yang lebih signifikan, maka dilakukan uji non-parametric kolmogrov-smirnov sebagai berikut:

Tabel 1. Uji Kolmogrov-smirnov

\begin{tabular}{llr}
\hline $\mathrm{N}$ & & Unstandardized Residual \\
\hline Normal Parameters & & 10 \\
\cline { 2 - 3 } & Mean & .0000000 \\
\cline { 2 - 3 } & Std. Deviation & .23425912 \\
\cline { 2 - 3 } & Absolute & .220 \\
\cline { 2 - 3 } & Positive & .220 \\
\cline { 2 - 3 } & Negative & -.124 \\
\hline Test Statistic & & .220 \\
\hline Asymp. Sig. (2-tailed) & & $.188^{\mathrm{c}}$ \\
\hline $\begin{array}{l}\text { a. Test distribution is Normal. } \\
\text { b. Calculated from data. } \\
\text { c. Lilliefors Significance Correction. }\end{array}$ & & \\
\hline
\end{tabular}


Berdasarkan hasil uji normalitas one sample Kolmogorov-Smirnov Test pada table diatas menunjukkan bahwa, nilai signifikan yang diperoleh sebesar 0,188 yang berarti nilai signifikan lebih besar dari 0,05. Sehingga dapat dikatakan data residual berdistribusi normal.

b. Uji Multikolinearitas

Tabel 2. Uji Multikolinearitas

\begin{tabular}{|c|c|c|c|c|c|c|c|c|}
\hline \multicolumn{9}{|c|}{ Coefficients $^{a}$} \\
\hline \multirow[b]{2}{*}{ Model } & & \multicolumn{2}{|c|}{$\begin{array}{l}\text { Unstandardized } \\
\text { Coefficients }\end{array}$} & \multirow{2}{*}{$\begin{array}{c}\text { Standardized } \\
\text { Coefficients } \\
\text { Beta }\end{array}$} & \multirow[b]{2}{*}{$\mathrm{T}$} & \multirow[b]{2}{*}{ Sig. } & \multicolumn{2}{|c|}{$\begin{array}{c}\text { Collinearity } \\
\text { Statistics }\end{array}$} \\
\hline & & $\mathrm{B}$ & Std. Error & & & & Tolerance & VIF \\
\hline 1 & (Constant) & 7.904 & 1.578 & & 5.010 & .002 & & \\
\hline & LDR & -.070 & .014 & -.883 & -4.924 & .002 & .995 & 1.005 \\
\hline & CAR & .016 & .050 & .057 & .320 & .758 & .995 & 1.005 \\
\hline
\end{tabular}

Berdasarkan tabel diatas, nilai Variance Inflation Factor (VIF) dan nilai tolerance pada masing-masing variabel sebagai berikut:

1) Variabel LDR memiliki nilai VIF $1,005 \leq 10$ dan nilai tolerance 0,995 $\geq 0,1$, sehingga LDR dinyatakan tidak terjadi multikolinearitas

2) Variabel CAR memiliki nilai VIF $1,005 \leq 10$ dan nilai tolerance 0,995 $\geq 0,1$, sehingga CAR dinyatakan tidak terjadi multikolinearitas Jadi, dapat disimpulkan bahwa antar variabel bebas tidak terjadi multikolinearitas terhadap data yang diuji.

c. Uji Heteroskedastisitas

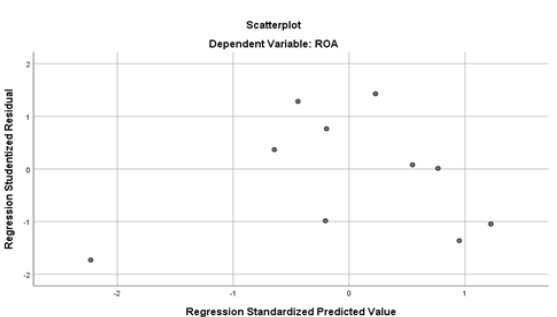

Gambar 3. Scatterplot

Berdasarkan gambar diatas, titik-titik yang ada didalam grafik scatterplot menyebar secara acak diatas dan dibawah garis angka nol. Titik-titik tersebut juga tidak membentuk pola tertentu, sehingga hal ini menunjukkan bahwa tidak terjadi heteroskedastisitas pada data yang diuji.

Tabel 3. Uji Heteroskedastisitas

\begin{tabular}{|c|c|c|c|c|c|c|}
\hline \multirow[b]{2}{*}{ Mode } & \multicolumn{6}{|c|}{ icients ${ }^{a}$} \\
\hline & & \multicolumn{2}{|c|}{ Unstandardized Coefficients } & $\begin{array}{l}\text { Standardized } \\
\text { Coefficients } \\
\text { Beta }\end{array}$ & $\mathrm{t}$ & Sig. \\
\hline 1 & (Constant) & -.734 & .695 & & -1.056 & .326 \\
\hline & LDR & .005 & .006 & .246 & .746 & .480 \\
\hline & CAR & .027 & .022 & .408 & 1.237 & .256 \\
\hline
\end{tabular}

Berdasarkan hasil uji hesterokedastisitas glejser pada tabel diatas, dapat dilihat bahwa untuk nilai signifikan pada variabel LDR $0,480>0,05$, artinya nilai signifikan LDR lebih besar dari 0,05, ini menunjukkan bahwa variabel LDR tidak terjadi hesterokedastisitas. Nilai signifikan pada variabel CAR 0,256 > 0,05, artinya nilai signifikan CAR lebih besar dari 0,05, ini menunnjukkan bahwa variabel CAR tidak terjadi hesterokedastisitas.

d. Uji Autokorelasi

Tabel 4. Uji Heteroskedastisitas

\begin{tabular}{|c|c|c|c|c|c|}
\hline \multicolumn{6}{|c|}{ Model Summary } \\
\hline Model & $\mathrm{R}$ & $\begin{array}{c}\mathrm{R} \\
\text { Square }\end{array}$ & $\begin{array}{l}\text { Adjusted R } \\
\text { Square }\end{array}$ & $\begin{array}{c}\text { Std. Error of the } \\
\text { Estimate }\end{array}$ & $\begin{array}{l}\text { Durbin- } \\
\text { Watson }\end{array}$ \\
\hline 1 & $.881^{\mathrm{a}}$ & .776 & .712 & .26562 & 2.254 \\
\hline
\end{tabular}

Berdasarkan tabel diatas, hasil uji autokorelasi Durbin Watson (DW
Test) memperoleh nilai sebesar 2,254 dengan menggunakan jumlah data (n) 
$=10$, jumlah variabel bebas $(\mathrm{k})=2$, dan tingkat signifikansi $5 \%$. Nilai batas bawah $\left(d_{L}\right)$ sebesar 0,697 , nilai batas atas $\left(d_{U}\right)$ sebesar 1,641 , nilai 4 $d_{L}$ sebesar 3,303 dan nilai $4-d_{U}$ sebesar 2,359. Berdasarkan dengan kriteria pengambilan keputusan dikatakan tidak terjadi autokorelasi, jika nilai DW berada diantara $d_{U}$ dan $4-d_{U}$ atau $d_{U}<d<4-d_{U}$. Hasil uji autokorelasi dalam penelitian ini yaitu 1,641 < 2,254<2,359, sehingga dapat dikatakan bahwa pada data penelitian tidak terjadi autokorelasi.

\section{Analisis Regresi Linier}

a. Regresi Linier Sederhana

1) Uji Regresi Linier Sedehana Loan to Deposit Ratio (LDR) terhadap Return On Asset (ROA)

Tabel 5. Uji Regresi Linier Sedehana Loan to Deposit Ratio (LDR)

\begin{tabular}{|c|c|c|c|c|c|}
\hline \multirow[b]{3}{*}{ Model } & \multicolumn{3}{|c|}{ Coefficients $^{a}$} & \multirow{3}{*}{$\mathrm{t}$} & \multirow{3}{*}{ Sig. } \\
\hline & \multicolumn{2}{|c|}{$\begin{array}{l}\text { Unstandardized } \\
\text { Coefficients }\end{array}$} & \multirow{2}{*}{$\begin{array}{c}\text { Standardized } \\
\text { Coefficients } \\
\text { Beta } \\
\end{array}$} & & \\
\hline & $\mathrm{B}$ & Std. Error & & & \\
\hline 1 (Constant) & 8.148 & 1.301 & & 6.261 & .000 \\
\hline LDR & -.070 & .013 & -.879 & -5.215 & .001 \\
\hline
\end{tabular}

Berdasarkan tabel diatas, didapatkan hasil persamaan dari regresi linier sederhana $\mathrm{Y}=8,148$ $0,070 X_{1}$

a) Nilai konstanta (a) sebesar 8,148 , artinya jika nilai Loan to Deposit Ratio (LDR) sebesar 0, maka nilai Return On Asset (ROA) sebesar 8,148\%.

b) Nilai koefisien regresi Loan to Deposit Ratio (LDR) terhadap Tabel 6. Uji Regresi Linier Sedehana Capital Adequacy Ratio (CAR)

\begin{tabular}{|c|c|c|c|c|c|c|}
\hline \multicolumn{7}{|c|}{ Coefficients $^{a}$} \\
\hline & & \multicolumn{2}{|c|}{$\begin{array}{l}\text { Unstandardized } \\
\text { Coefficients }\end{array}$} & \multirow{2}{*}{$\begin{array}{c}\text { Standardized } \\
\text { Coefficients } \\
\text { Beta }\end{array}$} & \multirow[b]{2}{*}{$\mathrm{t}$} & \multirow[b]{2}{*}{ Sig. } \\
\hline \multicolumn{2}{|c|}{ Model } & $\mathrm{B}$ & Std. Error & & & \\
\hline \multirow[t]{2}{*}{1} & (Constant) & 1.410 & 1.711 & & .824 & .434 \\
\hline & CAR & -.002 & .099 & -.008 & -.022 & .983 \\
\hline
\end{tabular}

Berdasarkan tabel diatas, didapatkan hasil persamaan dari regresi linier sederhana $Y=1,410$ $0,002 X_{2}$.

a) Nilai konstanta (a) sebesar 1,410, artinya jika nilai Capital Adequacy Ratio (CAR) sebesar 0, maka nilai Return On Asset (ROA) sebesar $1,410 \%$.
Return On Asset (ROA) sebesar 0,070, maka setiap nilai Loan to Deposit Ratio (LDR) mengalami peningkatan sebesar $1 \%$, nilai Return On Asset (ROA) mengalami penurunan sebesar $0,070 \%$.

2) Uji Regresi Linier Sederhana Capital Adequacy Ratio (CAR) terhadap Return On Asset (ROA)

. Analisis Regresi Berganda

Tabel 7. Analisis Regresi Berganda

\begin{tabular}{|c|c|c|c|c|c|c|}
\hline \multicolumn{7}{|c|}{ Coefficients $^{a}$} \\
\hline & & \multicolumn{2}{|c|}{$\begin{array}{l}\text { Unstandardized } \\
\text { Coefficients }\end{array}$} & \multirow{2}{*}{$\begin{array}{c}\text { Standardized } \\
\text { Coefficients } \\
\text { Beta } \\
\end{array}$} & \multirow[b]{2}{*}{$\mathrm{t}$} & \multirow[b]{2}{*}{ Sig. } \\
\hline \multicolumn{2}{|c|}{ Model } & B & Std. Error & & & \\
\hline \multirow[t]{3}{*}{1} & (Constant) & 7.904 & 1.578 & & 5.010 & .002 \\
\hline & LDR & -.070 & .014 & -.883 & -4.924 & .002 \\
\hline & CAR & .016 & .050 & .057 & .320 & .758 \\
\hline
\end{tabular}


Berdasarkan tabel diatas, didapatkan hasil persamaan regresi linier berganda $y=7,904-$ $0,070 X_{1}+0,016 X_{2}$, penjelasan dari hasil regresi linier berganda sebagai berikut:

1) Nilai konstanta (a) sebesar 7,904 , artinya jika nilai Loan to Deposit Ratio (LDR) dan Capital Adequacy Ratio (CAR) sebesar 0, maka nilai Return On Asset (ROA) sebesar $7,904 \%$.

2) Nilai koefisien regresi Loan to Deposit Ratio (LDR) terhadap Return On Asset (ROA) sebesar 0,070\%, maka setiap nilai Loan to Deposit Ratio (LDR) mengalami peningkatan sebesar 1\%, nilai Return On Asset (ROA) akan mengalami penurunan Sebesar $0,070 \%$.

3) Nilai koefisien regresi Capital Adequacy Ratio (CAR) terhadap Return On Asset (ROA) sebesar
0,016, maka setiap nilai Capital Adequacy Ratio (CAR) mengalami peningkatan sebesar 1\%, nilai Return On Asset (ROA) akan mengalami peningkatan sebesar $0,016 \%$.

\section{Koefisien Determinasi}

Tabel 8. Koefisien Determinasi Model Summary

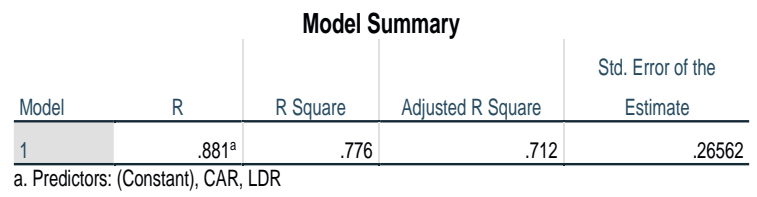

Berdasarkan tabel diatas, diperoleh nilai koefisien determinasi $\mathrm{R}\left(r^{2}\right)=0,881$, maka KD $=0,881^{2} \times 100 \%=0,776$ atau $77,6 \%$. Sisanya $100 \%-77,6 \%=22,4 \%$. Jadi dapat disimpulkan bahwa Loan to Deposit Ratio (LDR) dan Capital Adequacy Ratio (CAR) berpengaruh sebesar 77,6 \% terhadap Return On Asset (ROA), sedangkan sisanya $22,4 \%$ dipengaruhi oleh variabel lain yang tidak diteliti dalam penelitian ini.

\section{Uji Hipotesis}

a. Hipotesis Simultan (Uji F)

Tabal 9. Uji F

ANOVA $^{a}$

\begin{tabular}{|c|c|c|c|c|c|c|}
\hline \multicolumn{2}{|c|}{ Model } & Sum of Squares & $\mathrm{df}$ & Mean Square & $\mathrm{F}$ & Sig. \\
\hline \multirow[t]{3}{*}{1} & Regression & 1.711 & 2 & .856 & 12.126 & $.005^{\mathrm{b}}$ \\
\hline & Residual & .494 & 7 & .071 & & \\
\hline & Total & 2.205 & 9 & & & \\
\hline
\end{tabular}

Berdasarkan tabel diatas, hasil uji hipotesis simultan (uji F) diperoleh nilai $\mathrm{F}_{\text {hitung }} 12,126>F_{\text {tabel }} 4,46$ dengan signifikan $0,005<0,05$, berdasarkan hipotesis maka ho3 ditolak has

diterima. Kesimpulannya bahwa Loan to Deposit Ratio (LDR) dan Capital Adequacy Ratio (CAR) secara simultan berpengaruh signifikan terhadap Return On Asset (ROA).

b. Hipotesis Parsial (Uji t)

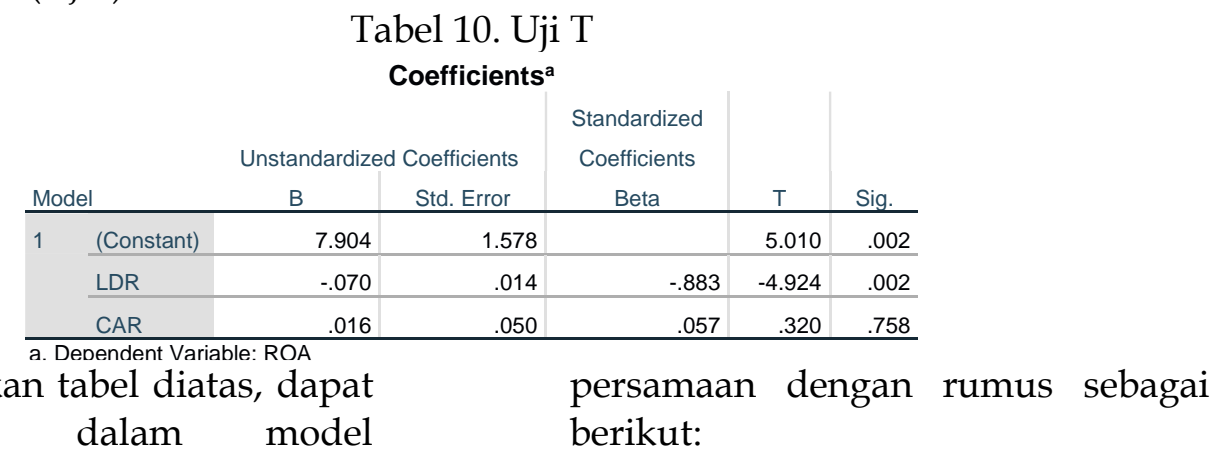


$t_{\text {tabel }}=(\mathrm{a} / 2 ; \mathrm{n}-\mathrm{k}-1)=(0,05 / 2 ; 10-$ $2-1)=0,025 ; 7=2,365$

1) Loan to deposit Ratio (LDR) terhadap Return On Asset (ROA)

Diketahui nilai signifikan sebesar $0,002<0,05$ dan nilai $t_{\text {hitung }}$ sebesar $4,924>t_{\text {tabel }}$ sebesar 2,365, berdasarkan hipotesis $\mathrm{H}_{01}$ ditolak $\mathrm{Ha}_{1}$ diterima. Kesimpulannya bahwa Loan to Deposit Ratio (LDR) secara parsial berpengaruh negatif signifikan terhadap Return On Asset (ROA).

2) Capital Adequacy Ratio (CAR) terhadap Return On Asset (ROA)

Diketahui nilai signifikan sebesar $0,758>0,05$ dan $t_{\text {hitung }}$ sebesar $0,320<t_{\text {tabel }}$ sebesar 2,365, berdasarkan hipotesis $\mathrm{H}_{02}$ diterima $\mathrm{Ha}_{2}$ ditolak. Kesimpulannya bahwa Capital Adequacy Ratio (CAR) secara parsial tidak berpengaruh terhadap Return On Asset (ROA).

\section{Pembahasan Penelitian}

1. Pengaruh Loan to Deposit Ratio (LDR) terhadap Return On Asset (ROA)

Berdasarkan hasil perhitungan statistik secara parsial (uji t) yang telah dilakukan diatas, diperoleh nilai $t_{\text {hitung }}$ dari Loan to Deposit Ratio (LDR) sebesar 4,924 nilai ini lebih besar daripada nilai $t_{\text {tabel }}$ sebesar 2,365. Nilai signifikan Loan to Deposit Ratio (LDR) sebesar 0,002 lebih kecil daripada nilai signifikan yang telah ditetapkan sebesar 0,05. Jadi apabila $t_{\text {hitung }}>t_{\text {tabel}}$, maka berdasarkan hipotesis $\mathrm{H}_{01}$ ditolak dan $\mathrm{Ha}_{1}$ diterima. Kesimpulannya bahwa Loan to Deposit Ratio (LDR) secara parsial berpengaruh negatif signifikan terhadap Return On Asset (ROA).

Hasil penelitian ini mendukung hasil penelitian dari Suwandi dan Oetomo (2017) yang menyatakan Loan to Deposit Ratio (LDR) berpengaruh negatif signifikan terhadap Return On Asset (ROA). Namun berbanding terbalik dengan hasil penelitian dari peling dan sedana (2018) yang menyatakan Loan to Deposit Ratio (LDR) berpengaruh positif signifikan terhadap Return On Asset (ROA).

2. Pengaruh Capital Adequacy Ratio (CAR) terhadap Return On Asset (ROA)

Berdasarkan hasil perhitungan statistik secara parsial (uji t) yang telah dilakukan diatas, diperoleh nilai $t_{\text {hitung }}$ dari Capital Adequacy Ratio (CAR) sebesar 0,320 nilai ini lebih kecil daripada nilai $t_{\text {tabel }}$ sebesar 2,365. Nilai signifikan Capital Adequacy Ratio (CAR) sebesar 0,758 lebih besar daripada nilai signifikan yang ditetapkan sebesar 0,05. Jadi apabila $t_{\text {hitung }}<t_{\text {tabel }}$, maka berdasarkan hipotesis $\mathrm{H}_{02}$ diterima $\mathrm{Ha}_{2}$ ditolak. Kesimpulannya bahwa Capital Adequacy Ratio (CAR) tidak berpengaruh terhadap Return On Asset (ROA).

Hasil penelitian ini mendukung hasil penelitian dari Rahman dan Isynuwardhana (2019) yang menyatakan Capital Adequacy Ratio (CAR) tidak berpengaruh terhadap Return On Asset (ROA). Namun berbanding terbalik dengan hasil penelitian dari Rembet dan Baramuli (2020) yang menyatakan bahwa Capital Adequacy Ratio (CAR) berpengaruh signifikan terhadap Return On Asset (ROA).

3. Pengaruh Loan to Deposit Ratio (LDR) dan Capital Adequacy Ratio (CAR) terhadap Return On Asset (ROA)

Berdasarkan hasil perhitungan statistik secara simultan (uji F) yang telah dilakukan, diperoleh nilai $F_{\text {hitung }}$ dari Loan to Deposit Ratio (LDR) dan Capital Adequacy Ratio (CAR) sebesar 12,126, nilai tersebut lebih besar dari $F_{\text {tabel }}$ sebesar 4,46. Dengan nilai signifikan Loan to Deposit Ratio (LDR) dan Capital Adequacy Ratio (CAR) sebesar 0,005 lebih kecil dari nilai signifikan yang ditetapkan sebesar 0,05. Jadi apabila $\mathrm{F}_{\text {hitung }}>\mathrm{F}_{\text {tabel}}$, maka berdasarkan hipotesis $\mathrm{H}_{03}$ ditolak $\mathrm{Ha}_{3}$ diterima. Kesimpulannya bahwa Loan to Deposit Ratio (LDR) dan Capital Adequacy Ratio (CAR) secara simultan berpengaruh 
signifikan terhadap Return On Asset (ROA). Dari nilai koefisien determinasi menunjukkan bahwa besarnya pengaruh Loan to Deposit Ratio (LDR) dan Capital Adequacy Ratio (CAR) terhadap Return On Asset (ROA) adalah 77,6\%, sedangkan sisanya sebesar $22,4 \%$ dipengaruhi oleh faktor lain yang tidak diteliti didalam penelitian ini.

\section{PENUTUP}

\section{Kesimpulan}

1. Hasil penelitian secara parsial (uji t) menunjukkan bahwa adanya pengaruh negatif dan signifikan pada Loan to Deposit Ratio (LDR) terhadap Return On Asset (ROA), dengan hasil nilai uji t_\{hitung\} 4,924 > t_\{tabel\} 2,365. Nilai signifikan $0,002<0,05$. Dengan hasil persamaan regresi linier sederhana yaitu $\mathrm{Y}=8,148$ - 0,070X_1, berdasarkan hipotesis maka $\mathrm{H}_{01}$ ditolak dan $\mathrm{Ha}_{1}$ diterima.

2. Hasil penelitian secara parsial (uji t) menunjukkan bahwa tidak adanya pengaruh pada Capital Adequacy Ratio (CAR) terhadap Return On Asset (ROA), dengan hasil nilai uji t_\{hitung\} 0,320 < t_\{tabel\} 2,365. Nilai signifikan 0,758 > 0,05 . Dengan hasil persamaan regresi linier sederhana yaitu $\mathrm{Y}=1,1410$ 0,002X_2, berdasarkan hipotesis maka $\mathrm{H}_{02}$ diterima dan $\mathrm{Ha}_{2}$ ditolak.

3. Hasil penelitian secara simultan (uji F) menunjukkan bahwa adanya pengaruh signifikan pada Loan to Deposit Ratio (LDR) dan Capital Adequacy Ratio (CAR) terhadap Return On Asset (ROA), dengan hasil nilai uji F_\{hitung\} 12,126> F_\{tabel\} 4,46. Nilai signifikan 0,005 < 0,05 . Dengan hasil persamaan regresi linier berganda yaitu $Y=7,904-0,070 X \_1$ + 0,016X_2, berdasarkan hipotesis maka $\mathrm{H}_{03}$ ditolak dan $\mathrm{Ha}_{3}$ diterima. Dan dari nilai koefisien determinasi menunjukkan bahwa besarnya pengaruh Loan to Deposit Ratio (LDR) dan Capital Adequacy Ratio (CAR) terhadap Return On Asset (ROA) adalah 77,6\%, sedangkan sisanya sebesar $22,4 \%$ dipengaruhi faktor lain yang tidak diteliti dalam penelitian ini.

\section{Saran}

1. Perusahaan harus melakukan peningkatan teladan seorang pemimpin yang baik, seorang pimpinan yang mampu menginspirasi karyawannya, sehingga karyawan dapat mencontoh hal-hal yang baik atau positif.

2. Perusahaan harus memperhatikan lingkungan sosial tempat kerja, menjamin perusahaan memiliki lingkungan kerja yang nyaman, agar karyawan merasa betah bekerja diperusahaan, dan merasa dirinya berada disekeliling orang-orang yang dapat menerimanya serta menghargai dirinya.

3. Perusahaan harus melakukan pengawasan terhadap kinerja karyawan agar tugas dan tanggung jawab yang telah diberikan dapat dijalankan dengan maksimal, agar karyawan tidak memperlambat penyelesaian tugas yang telah diberikan.

4. Kontribusi pengaruh antara disiplin kerja dan motivasi secara simultan terhadap kinerja karyawan sebesar $54,1 \%$, nilai ini masih bisa ditingkatkan dengan memprioritaskan karyawan dan kondisi masing-masing variabel bebas harus ditingkatkan secara signifikan. Oleh karenanya disarankan kepada penelitian berikutnya agar melakukan penelitian yang relevan dengan cara memperbaiki indikator yang masih tidak baik atau dengan menambah indikator pernyataan dan jumlah responden penelitian sehingga akan dapat lebih diketahui variabel yang paling memberikan kontribusi positif bagi perusahaan.

\section{DAFTAR PUSTAKA}

Fahmi, I. (2014). Analisis Laporan Keuangan. Cetakan Kedua. Bandung: Alfabeta.

Hantono. (2018). Konsep Analisa Laporan Keuangan Dengan Pendekatan Rasio dan SPSS. Yogyakarta: Deepublish. 
Haque, M. G., Nurjaya, N., Affandi, A., Erlangga, H., \& Sunarsi, D. (2021). Micro Financial Sharia Non-bank Strategic Analysis: a Study at BMT Beringharjo, Yogyakarta. Budapest International Research and Critics Institute (BIRCI-Journal): Humanities and Social Sciences, 4(2), 1677-1686.

Harahap, S., S. (2015). Analisis Kritis Atas Laporan Keuangan. Jakarta: Raja Grafindo Persada

Hariyani, I. (2010). Restrukturisasi dan Penghapusan Kredit Macet. Jakarta: PT Elex Media Komputindo Kompas Gramedia.

Harjito, A, \& Martono. (2014). Manajemen Keuangan. Yogyakarta: Ekonisia.

Hasibuan, M., S., P. (2016). Manajemen Dasar Pengertian dan Masalah. Jakarta: Bumi Aksara.

Kasmir. (2018). Analisis Laporan Keuangan. Jakarta: PT Raja Grafindo Persada.

Keown, A., J. (2011). Manajemen Keuangan Prinsip $\mathcal{E}$ Penerapan. Jakarta: PT Indeks.

Lubis, F., A, Isynuwardhana, D. \& Dillak, V,. J. (2017). Pengaruh LDR, NPL, CAR, NIM, BOPO terhadap ROA (Studi kasus pada Perusahaan Perbankan yang terdaftar di BEI Tahun 2012-2015). e-Procceding of Management, 4(3), 2355-9357.

Munawir. (2012). Analisis Laporan Keuangan. Yogyakarta: Liberty.

Najmudin. (2011). Manajemen Keuangan dan aktualisasi Syar'iyyah Modern. Yogyakarta: Andi.

Noryani, Y. B. G., Sari, W. I., Rosini, I., Munadjat, B., Sunarsi, D., \& Mahnun Mas' adi, G. (2020). Did ISO 45001, ISO 22000, ISO 14001 and ISO 9001 Influence Financial Performance? Evidence from Indonesian Industries. PalArch's Journal of Archaeology of Egypt/Egyptology, 17(7), 6930-6950.

Peling, I., A., A. \& Sedana, I., B., P. (2018). Pengaruh LDR, NPL, dan BOPO terhadap Profitabilitas pada PT BPD Bali Periode Tahun 2009-2016. E-
Jurnal Manajemen Unud. 7(6). 23028912.

Pratiwi, L., P., S., W. \& Wiagustini, N., L., P. (2015). Pengaruh CAR, BOPO, NPL dan LDR terhadap Profitabilitas Perusahaan Perbankan yang terdaftar di BEI Periode 2011-2013. E-Jurnal Manajemen Unud, 5(4), 2137-2166.

Pujiati, H., Sunarsi, D., Affandi, A., \& Anggraeni, N. (2021). Effect of ISO 9001: 2015 Quality Management Implementation in Education on School Performance. Journal of Contemporary Issues in Business and Government, 27(1), 1848-1855.

Rahman, R., A. \& Isyuwardhana, D. (2019). Pengaruh CAR, LDR, dan NPL terhadap Profitabilitas pada Industri Perbankan yang terdaftar di BEI Tahun 2013-2017. e-Proceeding Management. 6(1). 2335-9357.

Rembet, W., E., C. \& Baramuli, D., N. (2020). Pengaruh CAR, NPL, NIM, BOPO, LDR terhadap Return On Asset (ROA) (Studi Pada Bank Umum Swasta Nasional Devisa yang Terdaftar Di BEI Tahun 2015-2018). Jurnal EMBA. 8(3). 2303-1174.

Sofyan, M. (2019). Faktor-faktor yang mempengaruhi Profitabilitas Bank Perkreditan Rakyat (BPR) di Provinsi Jawa Timur. Jurnal Inspirasi bisnis dan Manajemen, 3(1), 2579-9401.

Sugiyono. (2017). Statistik Untuk Penelitian. Bandung: ALFABETA.

Sugiyono. (2019). Metode Penelitian Kuantitatif, Kualitatiff, dan RED. Bandung: ALFABETA.

Suhartono, A., Jati, W., \& Sunarsi, D. (2019). Pengaruh Earning Per Share Dan Return On Asset Terhadap Harga Saham Pada PT. Bank Negara Indonesia Tbk Periode 2009-2018. Jurnal Manajemen, Bisnis dan Organisasi (JUMBO), 3(3), 182-194.

Supardi. (2013). Aplikasi Statistika Dalam Penelitian . Jakarta: Change Publication.

Sutrisno. (2013). Manajemen Keuangan. Teori, Konsep, Dan Aplikasi.. Yogyakarta: Ekonisia. 